\title{
Correction to: Partially Overlapped Channel Assignment for Cloud-Based Heterogeneous Cellular and Mesh Networks
}

\author{
Saleem Iqbal ${ }^{1}$. Kashif Naseer Qureshi ${ }^{2}$. Saqib Majeed ${ }^{1} \cdot$ Kayhan Zrar Ghafoor $^{3}$. \\ Gwanggil Jeon ${ }^{4}$
}

Published online: 6 October 2021

๑) Springer Science+Business Media, LLC, part of Springer Nature 2021

\section{Correction to: Wireless Personal Communications https://doi.org/10.1007/s11277-021-09012-y}

In this article the author names Kashif Naseer Qureshi and Kayhan Zrar Ghafoor were incorrectly written as Kashif Qureshi and Kyan Zar Ghafoor.

The original article has been corrected.

Publisher's Note Springer Nature remains neutral with regard to jurisdictional claims in published maps and institutional affiliations.

The original article can be found online at https://doi.org/10.1007/s11277-021-09012-y.

Gwanggil Jeon

gjeon@inu.ac.kr

Saleem Iqbal

saleem@uaar.edu.pk

Kashif Naseer Qureshi

kashifnq@gmail.com

Saqib Majeed

saqib@uaar.edu.pk

Kayhan Zrar Ghafoor

kayhan.zrar@knu.edu.iq

1 University Institute of Information Technology, PMS UAAR, Rawalpindi, Pakistan

2 Department of Computer Science, Bahria University, Islamabad, Pakistan

3 Department of Computer Science, Knowledge University, University Park, Kirkuk Road, 44001 Erbil, Iraq

4 Department of Embedded Systems Engineering, Incheon National University, Incheon, South Korea 